Vol.10, \#6, Junio 2006

http://revista-redes.rediris.es

\title{
El cambio en las redes: una aproximación a las relaciones sociales desde el lenguaje, la representación y la institucionalización
}

\author{
Gabriel Vélez Cuartas, Departamento de Sociología - Universidad de Antioquia ${ }^{1}$
}

\begin{abstract}
Resumen
Este artículo pretende retomar los planteamientos de Giddens de la doble hermenéutica como fundamento epistemológico para resolver la tensión entre metodologías estructurales cuantitativas como el análisis de redes sociales y el uso de representaciones sociales y lenguaje para entender la realidad social desde metodologías cualitativas. Esto involucra la discusión de la relación entre análisis cualitativo y cuantitativo. Estos debates no han resuelto esta tensión más allá de la complementariedad en la aplicación técnica de instrumento para la recolección de información. Este artículo prentende realizar un aporte a estos planteamientos.
\end{abstract}

Palabras clave: Epistemología - Estructuración - Metodología - Análisis de redes sociales - Entrevista cualitativa.

\begin{abstract}
This paper pretends to get Giddens concept's double hermenutic. This will solve the tension between structural methodologies like network analysis and the use of social representations and language to understand the social reality. This involves the discussion of relationship between qualitative and quantitative analysis. These debates don't have resolve that tension beyond the complementary thecnical aplication of instruments for recolect information. This paper pretends to make a new output way for that discussion.
\end{abstract}

Key words: Epistemology - Structuration - Methodology - Social network analysis - Qualitative interview.

1 Departamento de Sociología. Enviar correspondencia a: Gabriel Vélez Cuartas; correo-e: gabrielvelezcuartas@yahoo.com.mx 


\section{El problema}

Los objetos de estudio abordados en las múltiples investigaciones dentro de las ciencias sociales ${ }^{2}:$ monografías $^{3}$, diagnósticos sociales situacionales contratados por alcaldías, la Gobernación y otras organizaciones gubernamentales en Colombia ${ }^{4}$, estudios de calidad de vida ${ }^{5}$, diagnósticos-propuestas ${ }^{6}$, estudios poblacionales 0 culturales se han desarrollado en una dicotomía insalvable entre el estudio de las representaciones sociales basadas en su mayoría en planteamientos del interaccionismo simbólico ${ }^{7}$ o estudios de tipo estadístico alimentados por un análisis estructural clásico que exaltan la descripción de una institucionalidad dada, reflejada en cifras y datos no dinámicos exaltando un paradigma positivista en la construcción de explicaciones sobre la realidad. Con respecto al uso de los paquetes metodológicos cuantitativos Briones dice que "la explicación estadística es una de las formas de explicación que con más frecuencia se utiliza en las ciencias sociales. En forma simplificada se suele decir que cuando una variable (fenómeno) está asociada a otra variable (otro fenómeno), la segunda explica a la primera si

\footnotetext{
2 Se toman como ciencias sociales las planteadas por Briones en su texto de Epistemología: Sociología, Ciencia Política, Educación, Psicología Social, Antropología y Geografía Social. Otras ciencias como Economía, Derecho o Historia tienen planteamientos epistemológicos distintos, los cuales no interesan a este texto debido al tipo de preocupaciones referidas acerca de las relaciones sociales. De otro lado hay otras disciplinas que retoman los planteamientos epistemológicos y metodológicos de las ciencias citadas para sus investigaciones como la comunicación y el trabajo social, por lo tanto también entran en nuestro campo de interés. Briones, Guillermo. Epistemología de las ciencias sociales. Bogotá: ARFO editores, 2002, p. 15

${ }^{3}$ En ciencias sociales podrían encontrarse tres tipos de monografías de corte empírico-analítico (la clasificación heurística es propia a partir de la experiencia investigativa y los ejercicios realizados por estudiantes): algunos estudios de corte cualitativo, bastante en boga no sólo por la afinidad epistemológica con los estudios de las representaciones y la relevancia del sujeto, sino también por los bajos costos que implica una investigación no estadística con amplias poblaciones. Algunos otros estudios que retoman fuentes secundarias y emplean datos estadísticos para dar comprensiones a sus objetos de estudio; y finalmente los diagnósticos que toman datos estadísticos o de representaciones sociales a veces con alguna claridad sobre sus fundamentos epistemológicos, otras veces no, pero finalmente resolviendo tal dicotomía con análisis que dividen en el mejor de los casos las conclusiones sobre la estructura por un lado y las representaciones por otro: las incidencias entre sujeto y estructura son vagas y explicadas o comprendidas desde una corriente o la otra y casi nunca en diálogo.

${ }^{4}$ Especialmente los planteados para los observatorios de infancia y familia o las múltiples investigaciones poblacionales acerca de la juventud, la mujer, el desplazamiento, etc. (cuya metodología más frecuente con los DRP construidos con base en epistemologías que privilegian la representación social y los imaginarios colectivos creados en la interacción discursiva)

${ }^{5}$ Especialmente de corte cuantitativo: arrojan cifras sobre los principales aspectos relacionados con necesidades básicas insatisfechas. También pueden encontrarse múltiples estudios sobre cobertura y calidad de la salud y la educación basados en cifras estadísticas.

${ }^{6}$ Estos intentan construir visiones sea de tipo culturalista entendiendo las interacciones de los sujetos en distintos procesos y concluir la mayoría de las veces la necesidad de la intervención sobre las representaciones y las interacciones de los sujetos mismos. De otro lado se pueden encontrar estudios de tipo más cuantitativo ofreciendo datos estadísticos sobre las funciones en los procesos y su eficiencia o suficiencia con respecto a teorías intermedias ya desarrolladas como propuestas para el mejoramiento.

${ }^{7}$ Ver Berger y Luckmann, La construcción social de la realidad; Blumer, H. El interaccionismo simbólico: perspectivas y métodos; Mead, George H. Espíritu, persona y sociedad; entre otros.
} 
antecede a la primera y existe una asociación más o menos fuerte entre ellas" ${ }^{8}$. En el mejor de los casos podrían encontrarse estudios de tipo empírico que retoman técnicas cualitativas para crear categorías divorciadas epistemológicamente de otras cuantitativas y que ven resuelta su dicotomía en el análisis empírico separado de ambos tipos de datos, tal vez conciliados por la teoría y no por la metodología y mucho menos por una visión epistemológica coherente ${ }^{9}$. Sería imposible a la luz de estos estudios asociar metodológicamente datos cualitativos con cuantitativos por sus supuestos epistemológicos, de un lado las representaciones evidenciadas en matrices interpretativas, de otro lado datos estadísticos que presentan una estructura (a veces funcional) desligada de la construcción representada, imaginada o construida desde el deseo, la voluntad, la motivación y la intencionalidad ${ }^{10}$. Es evidente la fragmentación del sujeto: de un lado quien construye su contexto y asiste a los cambios estructurales en su devenir discursivo, de otro lado el sujeto limitado en sus comportamientos por una estructura institucional donde este se desfigura. Nunca en diálogo desde las estrategias metodológicas empleadas.

Briones plantea uno de los problemas de la epistemología como

(...) la naturaleza del conocimiento que debe obtener la investigación social de los objetos que estudia. Aquí, la dicotomía se presenta en la elección de un enfoque cuantitativo, por un lado, o un enfoque cualitativo, por otro. El enfoque cuantitativo buscará la medición de los fenómenos sociales, en particular, la medición individual de las propiedades que se dan en esos objetos, mediante las llamadas variables, de tal modo que sea posible la utilización de las técnicas estadísticas del caso. La alternativa cualitativa, por su lado, emplea un enfoque holístico, o sea, un estudio del objeto tomado en su totalidad, para lo cual deberá utilizar técnicas cualitativas adecuadas para ese propósito. ${ }^{11}$

\footnotetext{
${ }^{8}$ Op. cit. Briones, p. 53

9 J esús Galindo plantea la diferencia entre técnicas, metodologías y epistemologías: la primera responde a un asunto meramente operativo de aplicación en el campo, la segunda al por qué se hacen las cosas así y no de otra forma, la tercera es la dimensión superior dónde se define el para qué y el para quién se hace investigación. Ver: Galindo Cáceres, Jesús. Técnicas de Investigación en Sociedad, Cultura y Comunicación. México: Addison Wesley Longman, 1998, p. 23. Aquí se propone que si bien hay una aplicación técnica en estas investigaciones bastante rigurosa, no hay una ruta metodológica coherente que permita poner en diálogo lo cualitativo y lo cuantitativo, especialmente en el estudio de las relaciones sociales y la respuesta a la dicotomía sujeto-estructura.

${ }^{10}$ Este tipo de estudios, como el diagnóstico social situacional de la niñez en Medellín (en este momento en ejecución), presenta una estructura compleja de datos que por un lado da cuenta de datos estadísticos construidos y por el otro busca en las representaciones sociales las comprensiones construidas por los mismos sujetos de su realidad. El análisis permite salvar la dicotomía a través de un supuesto institucional: de un lado la estructura de atención que necesita estadísticas para validar sus programas, de otro las representaciones sociales que intentan presentar soluciones o visiones problemáticas y problematizadoras al contexto cotidiano inmediato. Lo institucional estructural por un lado, lo comunitario cultural, por otro.
}

${ }^{11}$ Op. cit. Briones, pp 13-14. 
Al seguir los planteamientos de Briones, nos damos cuenta que el problema es más complejo que una elección entre metodologías cualitativas o cuantitativas: plantea una dicotomía entre paradigmas de corte explicativo que asumen la explicación de causas a partir de una deducción de la teoría general planteada, y las de la comprensión o interpretación que plantean la realidad no ajena a las visiones o representaciones que los mismos investigadores puedan hacer de ella, es una interacción constante entre conciencia propia y conciencia externa; es una negociación constante de representaciones de la realidad.

Los esfuerzos realizados hasta el momento para integrar una visión cualitativa con una cuantitativa se han centrado básicamente en la validación de datos desde la utilización de técnicas cualitativas o cuantitativas. En la encuesta social como paquete metodológico a menudo se utilizan entrevistas a profundidad para hacer seguimiento a las poblaciones muestra. En las investigaciones cualitativas se utiliza un proceso de triangulación para validar los datos en el cual a menudo se utilizan datos estadísticos. Pero no hay un diálogo metodológico, sólo técnico, y las perspectivas empleadas no se salen de los marcos planteados en una u otra elección metodológica (y epistemológica). Lo explicativo continúa en su ámbito de entender el mundo como algo dado, lo comprensivo o interpretativo no cede mayor parte de su terreno a entender la sociedad desde las profundidades de las construcciones del lenguaje en el sujeto que propone el mundo que le rodea aislado de estructuras no lingüísticas. Finalmente, la validación pretendida queda en suspenso metodológico, pues no hay una justificación epistemológica que permita entender por qué una metodología que se basa en teorías generales sobre la sociedad, permite su validación a partir de las percepciones y representaciones construidas de los sujetos y viceversa.

Por último, para poder centrar nuestro problema aún más se propone el abordaje de este desde las relaciones sociales como objeto de estudio, lo cual lleva inmediatamente a la dicotomía entre estructura y sujeto como se dijo anteriormente.

Desde el paradigma explicativo en las investigaciones empírico-analíticas, la relación sujeto-estructura sólo puede ser vista a partir de teorías generales que en su mayoría no toman en cuenta al sujeto (funcionalismo, estructural-funcionalismo, funcional-estructuralismo). Las investigaciones de corte empírico analítico, preocupadas por las relaciones sociales, se encargarán de hacer fotografías (dicho de forma metafórica) de las estructuras sociales sea a partir de datos estadísticos o a través de la graficación de estructuras relacionales con técnicas matemáticas. 
Cualquier fenómeno social será producto de la estructura y sólo puede ser explicado a través de ésta. La estructura representa lo inmanente, el cambio no es percibido y finalmente desechado, por ello el sujeto es irrelevante, en tanto es expresión de relaciones estructurales abstractas.

Diría I báñez como parte de una crítica a la estructura preestablecida en su texto los Avatares del Sujeto: "El sujeto es efecto, no causa, del orden simbólico. El orden simbólico pre-existe a los individuos: cuando nacen tiene ya preparado, para cada uno, su lugar (en el conjunto de las relaciones sociales)"12. Sin embargo no es el orden de la construcción lingüística la preocupación sino las relaciones desencadenantes de lo social. Y al preguntarse por el todo, se pierde la complejidad de la estructuración. Las causas de la estructura, lo estructurante, queda perdido en el mapa abstracto.

Desde el paradigma comprensivo, el objeto que prevalece es el lenguaje. Las relaciones sociales desde este punto de vista, sólo pueden ser explicadas a partir del sentido construido por los sujetos, reflejado en sus expresiones lingüísticas. De Peirce a Habermas, pasando por la fenomenología, la hermenéutica y el interaccionismo simbólico, el mundo de la investigación se ha transformado. Este no es el mismo desde la aparición en la escena de las ciencias sociales del lenguaje. Allí podrían identificarse claramente dos corrientes, una inaugurada por Peirce ${ }^{13}$ y la otra por Saussure ${ }^{14}$. El primero da relevancia a la producción de sentido a partir de la creación de significados en situación pragmática: el lenguaje es un juego de conexiones de signos con otros signos que se van construyendo en un incesante proceso de pensamiento ligado a la práctica y la experiencia de los sujetos. Las cosas adquieren sentido en tanto el sujeto le da un uso específico a las cosas que le rodean y les asigna un concepto. De otro lado, Saussure se preocupa no tanto por el sentido que se desprende de las operaciones pragmáticas del sujeto, sino más bien del lenguaje como estructura preexistente e inmanente, con reglas propias, las cuales los sujetos mismos entran a conjugar para dar sentido y construir sentido.

Estas propuestas de comprensión del mundo a partir del lenguaje, tal vez las más representativas como precursoras del giro lingüístico (sin desconocer todos los

\footnotetext{
12 Ibáñez, Jesús. Los avatares del sujeto. En: I báñez, Jesús (comp.) Nuevos Avances en la Investigación Social I. Barcelona: Proyecto A, 1998. p. 56

13 Ver: Deladalle, Gérard. Leer a Peirce hoy. Barcelona: Gedisa, 1996; y Peirce, Charles Santiago Sanders. El hombre, un signo: el pragmatismo de Peirce. Barcelona: Editorial Crítica, 1988

${ }^{14}$ Ver: Saussure, Ferdinand de. Curso de lingüística general. Argentina: Losada, 1974
} 
esfuerzos de la fenomenología y la hermenéutica), lograron proponer un giro comprensivo a la metodología en las ciencias sociales. Ello implica ver los fenómenos sociales de dos formas básicas: uno como expresión de una estructura lingüística que constriñe sus elecciones de sentido, de otro lado, un sujeto activo, capaz de proponer el mundo mismo y proponer su visión de mundo desde su cotidianidad única e irrepetible. El eje de ambas propuestas estructurales o estructurantes es el lenguaje y el mundo puede ser estudiado, investigado y escudriñado desde el lenguaje mismo.

Se hace visible lo estructurante de lo social, pero la visión recortada no permite ver el bosque relacional en el cual los sujetos, portadores de lenguaje y constructores de sentido, se desenvuelven. Se hacen relevantes las relaciones sociales establecidas por los sujetos en su contexto inmediato, pero se pierde la visión sistémica más allá de los sentidos otorgados por los sujetos entrevistados u observados en el campo. Se sabe de las percepciones de mundo de los sujetos mismos pero no de su relación con la estructura total. La única posibilidad presentada es la agregación de datos estadísticos epistemológicamente divorciados en la construcción del paquete metodológico, en un eclecticismo sórdido y sin bases sólidas.

Si bien enfoques comprensivo y explicativo abordan el problema de las estructuras, lo hacen desde perspectivas diferentes e irreconciliables metodológicamente hasta el momento en la escena local y regional. $Y$ de nuevo se subraya metodológicamente, pues la teoría social ha dado ya pasos importantes en la construcción de un entorno conceptual que haga viable una exploración de este tipo.

Para encontrar la solución a este problema tendríamos que tener en cuenta dos asuntos básicos: la naturaleza de lo datos sociales (metodología-tecnología) y la concepción de la relación investigador-objeto (epistemología-metodología). Ambos asuntos se tratarán imbricados en los planteamientos de los paquetes metodológicos expuestos a saber: análisis de redes sociales y entrevista cualitativa. Esta amalgama de asuntos se justifica en el tipo de enfoque teórico propuesto que se desarrollará con amplitud en los próximos apartados. Al final se planteará una propuesta metodológica con base en una corriente epistemológica adecuada haciendo una conjugación de los elementos expuestos. 
En este apartado se tomarán dos tipos de programas metodológicos, uno dentro del paradigma explicativo: el análisis de redes sociales, y otro dentro del paradigma comprensivo: la entrevista cualitativa. La pretensión es describir sus potencialidades metodológicas dentro de cada paradigma y finalmente rescatar los elementos que permiten generar un diálogo metodológico entre estructura y sujeto.

\section{Análisis de Redes Sociales}

El análisis de redes sociales "no aclara la relación entre la relación real y la representada, no ponen a la luz la naturaleza de las representaciones del porqué se elige uno y no otro. Describe situaciones estáticas, estructuras, pero no procesos. El tiempo no cuenta para nada". ${ }^{15}$

No es muy procedente comenzar criticando lo que se defenderá como una de las metodologías base para sostener el postulado de la posibilidad de diálogo metodológico entre paquetes que tradicionalmente han estado divorciados por su tradición explicativa o comprensiva. Sin embargo, esta crítica propone de entrada un tema importante: el análisis de redes sociales es estático (en el sentido metodológico y con posibilidades de predicción sobre eventos estructurales más no estructurantes) y no da cuenta de la realidad estructurante, con los desarrollos matemáticos que le han sido agregados para su análisis. Este argumento será central para dos asuntos: uno para dar cuenta de la naturaleza de los datos producidos por este paquete metodológico (lo que implica inclusive una visión de la realidad que es sumamente importante para nuestro planteamiento), y dos, para partir de que lo que aquí es visto como desventaja, puede ser tomado a favor en algún tipo de análisis descriptivo retomando el mundo de las representaciones planteado por el lenguaje. Pero para poder continuar habrá que aclarar la procedencia y los postulados de este paquete metodológico.

Lo primero que habría que decir es que está metodología es estructural. De hecho, el Análisis de Redes Sociales (ARS), es también conocido como análisis estructural. Las razones son dadas por Barry Wellman:

\footnotetext{
15 Opcit. Ibáñez, p. 36. Es importante aclarar que en la actualidad existen algunos avances en la consideración de la variable tiempo para realizar análisis compartivos entre una estructura de relaciones en donde participan distintos actores considerada en el tiempo fotografiando los mismos actores en intervalos periódicos para ver la evolución de la estructura misma (ver Jorge Gil-Mendieta y Alejandro Ruíz (redes variables en el tiempo: visualización con Pajek, Vol. 6 de esta misma publicación), trabajos de Snijders o las mismas descripciones de De Nooy, Mrvar y Batagelj en el texto citado de ellos en este artículo. Las comprensiones surgen del plantemiento de hipótesis acerca del comportamiento derivado de la estructura de relaciones, pero el papel de la agencia y la complejidad dentro de un esquema más allá de la relación causa-efecto, es desestimado.
} 
1. El comportamiento es interpretado en términos de restricciones estructurales sobre la actividad, antes que en términos de fuerzas internas existentes dentro de las unidades (e.g., "socialización en vez de normas"), las cuales impulsan el comportamiento con un ímpetu voluntarista, a veces hasta teleológico, hacia una meta deseada.

2. El análisis se centra en las relaciones entre unidades, y no en la clasificación de las unidades en categorías definidas por atributos internos (o esencias) de dichas unidades.

3. Una preocupación central es la manera cómo los patrones de relaciones entre múltiples alter afectan, en conjunto, el comportamiento de los miembros de la red. Por tanto, no se asume que los miembros de la red sólo participan en múltiples duetos con alter separados.

4. La estructura es tratada como una red de redes que puede estar, como no, dividida en grupos discretos. No se asume a priori que los grupos fuertemente cerrados sean, de manera intrínseca, los bloques de construcción de la estructura.

5. Los métodos analíticos tratan directamente con la naturaleza relacional - modelada en términos de patrones - de la estructura social, para así completar - y a veces sustituir - los principales métodos estadísticos que requieren de unidades independientes de análisis. ${ }^{16}$

EI ARS se plantea como una metodología de visualización de las estructuras sociales construidas a partir de relaciones constituidas en intercambios y flujos. Son estas relaciones las que determinan el comportamiento de los sujetos, las organizaciones, los grupos, en fin, los diversos actores sociales. La pretensión de éste es acumular una gran riqueza de datos relacionales que permitan describir la estructura y a partir de allí, comprender el comportamiento humano y sus productos asociativos (grupos y organizaciones).

Nadel define la estructura social: "Llegamos a la estructura de una sociedad abstrayendo de la población concreta y de su comportamiento concreto el esquema o red (o sistema) de relaciones que prevalecen entre individuos en su capacidad de desempeñar roles los unos respecto de los otros."17

\footnotetext{
16 Wellman, Barry. El análisis estructural: del método y la metáfora a la teoría y la sustancia. Monográfico "Análisis de Redes Sociales: la consolidación de un paradigma interdisciplinar".

Madrid, 22 de junio de 1999 (número 33), p. 3 En línea: http://www.ucm.es/info/pecar/Docu.htm

${ }^{17}$ Nadel, S. F. Teoría de la Estructura Social. Guadarrama: Madrid, 1966, p. 42
} 
El ARS produce abstracciones del mundo social a partir de las relaciones concurrentes entre los individuos. De allí se deduce algo y es el carácter de las relaciones sociales. Estas sólo pueden ser vistas como patrones. Sólo hay relación social si los flujos o intercambios son concurrentes. Las interacciones eventuales no son categorías de análisis a menos que puedan ser entendidas dentro de algún tipo de patrón más o menos continuo de flujos y contraflujos.

“Una relación no es más que una semantización de la regularidad de un proceso real. Regularidad no sólo contrastada sino regularidad resultante de una específica enunciación y tipificación, socialmente producida: el lenguaje de las relaciones sociales es el lenguaje de la regulación social" ${ }^{18}$. Ello implica la comprensión de las relaciones sociales no como hechos en sí, sino como comprensiones de hechos tipificados, aceptados socialmente e institucionalizados.

La investigación empírica en sociología no construye hechos relacionales: se contenta con registrar y sistematizar las enunciaciones socialmente producidas sobre estos hechos. Por ello los estudios empíricos describen las racionalizaciones o semantizaciones con que actores sociales, individuales o colectivos más o menos institucionalizados, estabilizan y regulan procesos sociales estructuralmente determinados. Las semantizaciones relacionales son, pues, de orden institucional y no estructural, aunque exista una relación dialéctica entre ambos órdenes de realidad social. Por lo tanto la conciencia de los actores sociales, sus valores, ideologías y racionalizaciones diversas es conciencia de lo institucional y no de lo estructural. Sin embargo, las racionalizaciones de los actores son elementos reguladores de la dinámica estructural misma, con lo que la relación entre lo ideológico y lo estructural es recíproca y dinámica, irreductible a la determinación mecánica de la primera por la segunda. ${ }^{19}$

Lo que reafirma la comprensión de la estructura como una abstracción únicamente visible o expresada en las comprensiones de los sujetos de sus conductas, intercambios e interacciones, semantizadas y clasificadas en patrones de relaciones más o menos estables.

Uno de los aspectos interesantes de este planteamiento de la naturaleza estructural de los datos relacionales en el ARS, es su conexión con el lenguaje, pues la única forma posible de clasificar datos es a través del leguaje y sólo el lenguaje puede expresar patrones existentes, tipificados a través de la experiencia de los mismos actores. El problema a mi modo de ver, está expresado en la asociación entre

\footnotetext{
${ }^{18}$ Pizarro, Narciso. Tratado de Metodología de las Ciencias Sociales. Madrid: Siglo XXI, 1998. p. 386

${ }^{19}$ I bid. p.p. 386-387
} 
estructura y lenguaje, o dicho en términos de Pizarro: semantizaciones institucionalizadas. Allí hay un presupuesto de fondo y es una comprensión del lenguaje bastante cercana a la lingüística Saussureana de la forma en que se presenta en este texto.

En la lingüística general de Saussure el lenguaje es considerado como un sistema estructurado, organizado por convención social. Su preocupación está en descubrir las regularidades que permiten dar sentido al mundo social. El signo lingüístico en Saussure, está compuesto por una imagen acústica (el significante) y un concepto (el significado). Ambos están ligados a lo que llama lengua, la cual está ligada a una inmutabilidad que está encadenada a una inercia estructural e histórica. Pero a la vez es mutable, característica ligada a un desplazamiento de la relación entre significante y significado propio de la continuidad de la lengua. Ello querría decir que se pueden encontrar patrones institucionalizados que sólo se modifican a partir de las transformaciones históricas de las imágenes acústicas o significantes. La lengua no es dinámica, o sólo puede ser vista de forma dinámica en lapsos temporales amplios, a través de generaciones. Ello podría asimilarse a la acepción de Pizarro acerca de las relaciones sociales, consideradas como semantizaciones institucionalizadas históricamente acerca de los hechos ${ }^{20}$. Ello llevaría a entender que la asignación de sentido a los comportamientos e interacciones estaría ligada a una concepción inmutable de la lengua, en la que se constituyen significaciones de mundo consensuadas históricamente por espacios sociales de tipo monolítico. Las estructuras son fijadas institucionalmente y no dan lugar a formas flexibles de comprensión de construcción de lo social.

Finalmente Saussure considera que los signos son construidos de forma arbitraria, no hay una relación entre la acción directa de los actores sociales y la constitución de sentido. El sentido se otorga de forma arbitraria. De lo que se puede deducir que las estructuras son monolíticas, generadas históricamente, pero se ha llegado a ellas de forma aleatoria. Somos lo que somos por devenir histórico y sin ninguna participación de los sujetos (que significan y dan sentido) en su construcción.

Esta concepción lleva también a otra deducción. El mundo puede ser explicado por estructuras preestablecidas y dadas. Ello nos llevaría a la pregunta: ¿quién define y valida la descripción de esta estructura inmanente? La primera respuesta, serían las convenciones socialmente construidas. Sin embargo, sólo puede validarse una

\footnotetext{
${ }^{20}$ Para profundizar en estas acepciones ver: Opcit. Saussure.
} 
convención en tanto existan sujetos que den sentido. Las estructuras no pueden ser simple expresión de una institucionalidad dada, en las cuales los sujetos mismos no pueden acceder a la estructura y su comprensión por sus semantizaciones institucionalizadas. De todos modos, según la concepción estructural inmanente, habría un observador, este observador a través de sus herramientas lingüísticas y procedimientos expertos podría abstraer del mundo social una comprensión estructural de todas estas relaciones sociales dadas al mundo de forma cuasi-ontológica.

Esta concepción nos llevaría a un problema más en cuanto al problema de la observación de estas estructuras inmanentes. Habría que entender la idoneidad del observador para ejecutar tales funciones. Para discernir este dilema de elección de observadores tendríamos que adentrarnos a una perspectiva de la significación y la semantización construida desde el pragmatismo, lo que modifica nuevamente la concepción de la naturaleza de los datos en el ARS, y tal vez descubramos que el problema no es de elección de observadores idóneos, inclusive cuestionando un postulado que valide esta construcción metodológica desde un paradigma explicativo.

La pregunta fundacional del pensamiento Peirceano es: ¿cómo se reconoce una idea clara y precisa? ${ }^{21}$ Se pregunta por cómo pensamos y no tanto por la relación del pensamiento con la realidad. La preocupación es distinta a la Saussureana. Saussure está preocupado por entender la lengua y sus regularidades. En Peirce la pregunta por la realidad se desvanece y se transforma en una indagación por la realidad del pensamiento.

Siempre que se piensa, se tiene la conciencia en algo sobre lo que se piensa (sensación, imagen, representación, concepto) que sirve como signo. Ese signo funciona de tres maneras para Peirce:

- Un signo es signo para un pensamiento que lo interpreta (interpretante).

- Es signo en lugar de algo del que es equivalente en este pensamiento (objeto).

- Es signo en algún respecto al objeto que lo conecta con el objeto (representamen).

\footnotetext{
${ }^{21}$ Ver introducción de Op. cit: Deladalle.
} 
El signo se constituye en la naturaleza misma del pensamiento. Cada pensamientosigno se conecta con otro pensamiento-signo lo cual hace que el proceso de pensar tenga finitud sólo en el cese de funciones cerebrales. Los signos encadenan otros signos que hacen dar sentido a la realidad inaccesible para el ser humano excepto por esta mediación sígnica. Este planteamiento responde parcialmente a la pregunta de Peirce. Hay un problema más y es la relación de este pensamiento signo con la realidad. Para Peirce el acceso sólo puede hacerse a través de procesos epistémicos que permiten que ese signo sea algo en lugar de algo. El origen de este proceso epistémico, es la inferencia. Inferimos que existen cosas y esa inferencia es impulsada por la experiencia y la práctica, esa experiencia es significativa y conecta signos con otros signos que permiten dar sentido a la realidad percibida en el proceso epistémico. Este planteamiento inaugura en el pensamiento occidental el pragmatismo, el cual ha fundamentado grandes corrientes de pensamiento y podemos encontrarla inclusive en las raíces del pensamiento habermasiano en los planteamientos de su acción comunicativa ${ }^{22}$.

Si bien la lengua preexiste al sujeto y pueden encontrarse patrones más o menos estables en su configuración, lo cual permite en últimas hablar de cultura, sociedad, grupos humanos, etc., también es cierto que esa lengua sólo puede ser entendida en un contexto dinámico constante y sólo se materializa en la acción concreta y específica intersubjetiva. El lenguaje se constituye en situación pragmática:

Las estructuras sintácticas o morfemas pueden tener solamente una función pragmática específica; ciertos significados están sistemáticamente relacionados con ciertos actos de habla; la interpretabilidad, hasta de frases aisladas y de cláusulas, requiere la referencia y las condiciones de conocimiento del mundo, y en las cláusulas de las oraciones compuestas pueden conectarse sólo con un tópico del discurso que pueden exceder el límite de la frase, requiriendo una macro semántica de secuencias específicas. ${ }^{23}$

Las semantizaciones institucionalizadas sólo adquieren sentido en un contexto pragmático. Ello querría decir que el observador se constituye en centro fundamental de la construcción semántica, pues sólo desde la experiencia validada con otras experiencias se puede acordar la designación de estructuras. El decir que el observador se hace el centro, se infiere no la idoneidad especial adquirida por acumulación de conocimientos, sino por los procesos epistémicos que emprende. La

22 Ver: Vélez Cuartas, Gabriel J. "Semiótica y acción comunicativa: Una ruta entre Pierce, Apel y Habermas", en Andamios. Revista de Investigación Social, Año 1, Número 2, Junio 2005, Colegio de Humanidades y Ciencias Sociales, Universidad Autónoma de la Ciudad de México, pp. 173-195

${ }^{23}$ van Dijk, Teun. Texto y Contexto. Madrid: Cátedra. Madrid. 1980. p. 39 
lectura construida como abstracción de la estructura, no es producto de un retiro del mundo, sino la producción de inferencias comprometidas con la experiencia subjetiva y que siempre deberán estar en negociación con los observados y sus propios procesos epistémicos ${ }^{24}$.

No se niega la utilidad de comprender el mundo como estructura de relaciones, flujos y contraflujos de relaciones sociales. Es también imposible afirmar que el mundo se construye en cada golpe de expresión de existencia o en cada elaboración pragmática de la realidad, ello sería afirmar que la sociedad se crea a cada segundo en cada acción, y que la historia y la herencia no existen. El pragmatismo agrega una nueva perspectiva: el sentido dado al mundo, al comportamiento y a las interacciones, retoman elementos institucionales consolidados en la historia y el tiempo, pero se resignifican en las circunstancias en que son empleados.

Las semantizaciones institucionalizadas están atravesadas por la experiencia de mundo del observador. No se propone tampoco que las instituciones sean producto de la subjetividad, sino más bien que los procesos de institucionalización establecen una relación dialéctica entre la experiencia de mundo de los sujetos y las convenciones y relaciones establecidas socialmente. Ello implicaría que las estructuras, como constructos racionales, sólo pueden ser descritas en contextos específicos, de acuerdo a la complejidad de relaciones históricas establecidas, pero también de acuerdo a las situaciones prácticas en las que se desenvuelven los actores resignificando y reconstituyendo la estructura misma (o las abstracciones de las relaciones sociales que es lo mismo). Las observaciones estarían determinadas por la experiencia del observador y por las mismas relaciones establecidas entre los observados, que al entrar en contacto con el observador, se convierten ellos mismos en observadores del observador que observa. A ello diría Varela:

\footnotetext{
${ }^{24}$ Sin embargo más adelante volveremos con el problema del observador, sólo interesaba ponerle en el lugar adecuado con respecto al paquete metodológico en este apartado.
} 
Es fascinante que el mundo sea así de plástico, ni subjetivo ni objetivo, ni unitario y separable, ni dual e inseparable. Esto apunta tanto a la naturaleza del proceso, que podemos percibir en la totalidad de su calidad formal y material así como también a los límites fundamentales de aquello que podemos comprender de nosotros mismos y del mundo. Demuestra que la realidad no está constituida sencillamente a nuestro antojo, porque esto significaría que podemos elegir un punto de salida desde adentro. Prueba además que la realidad no puede entenderse como algo objetivamente dado, como algo que recogemos, porque esto significaría suponer un punto de partida externo. Demuestra de hecho una ausencia de fundamento sólido de nuestras experiencias, en las cuales nos son suministradas determinadas regularidades e interpretaciones, fruto de nuestras experiencias, en las cuales nos son suministradas determinadas regularidades e interpretaciones, fruto de nuestra historia conjunta como seres biológicos y sociales. Dentro de estas áreas de historia común que reposan sobre acuerdos tácitos, vivimos en una aparentemente interminable metamorfosis de interpretaciones que se suceden. ${ }^{25}$

Estos planteamientos llevan directamente a la redefinición de relación social: si retomamos nuevamente el sentido aportado por Pizarro, podríamos decir que una relación social se constituye de patrones de intercambio, clasificados como tal por funciones del lenguaje convenidas socialmente, que son construidas en situación pragmática por los observadores y que responden a operaciones y funciones que se han construido históricamente. Ello implicaría una gran complejidad de estructuras que se imbrican y que están en constante movimiento por las mismas interacciones entre los actores.

Sería imposible de esta forma dar una característica de inmanencia a la abstracción graficada (grafos) como estructura por el investigador social. Esa estructura propuesta como abstracción gráfica, expresada en relaciones, puede ser reinterpretada de múltiples formas, proponiendo a los sujetos sociales bosquejos de relaciones entre sujetos que sólo pueden ser entendidas en la experiencia de los múltiples observadores que resignifican la propuesta del investigador mismo. Más allá de la gráfica misma, el bosquejo de estructura, no es sólo susceptible de múltiples interpretaciones, son múltiples las posibilidades estructurales que pueden constituirse en el diálogo entre lo histórico y heredado con la experiencia subjetiva. El relato limitado por la estructura, pero reconstituido en la experiencia individual, generando nuevas posibilidades, dentro de los límites establecidos, pero con posibilidad de ruptura.

\footnotetext{
${ }^{25}$ Varela, Francisco. Historia de la Reflexividad. En: En: I báñez, Jesús (comp.) Nuevos Avances en la Investigación Social I. Barcelona: Proyecto A, 1998. p. 106
} 
EI ARS se propone como programa metodológico para dar cuenta de relaciones antes invisibles para el observador. Esta visibilidad abre nuevas puertas a comprensiones sobre el entorno del sujeto mismo y a sus posibilidades reales e imaginadas de acción. De esta forma el sujeto reaparece en la estructura no como un producto de ésta, sino como un actor capaz de leer las relaciones sociales en las que está inmerso para tomar decisiones con sus posibilidades de acción y percepción del mundo. Si nos limitamos a las comprensiones que proponen un sujeto encadenado a la estructura, sería imposible entender los giros históricos de la sociedad en circunstancias adversas o la generación de nuevas formas de comprensión en medio de estructuras rígidas y totalitarias.

Estos planteamientos nos llevan a un segundo asunto de los planteados en el principio de este apartado: las estructuras presentadas metodológicamente por el ARS son de tipo fotográfico y suponen el sentido a partir de las interpretaciones de un observador externo. Las relaciones por las cuales se define la estructura, e inclusive la definición de la estructura misma ${ }^{26}$. Pero para comprenderlo tendríamos que describir un poco más la herramienta utilizada.

Vladimir Batagelj, Wouter de Nooy y Andrej Mrvar plantean que "El análisis de redes sociales exploratorio consta de 4 partes: la definición de una red, manipulación de una red, determinación de formas estructurales (structural features) e inspección visual”27. La definición de una red está determinada por la elección de tipos de relaciones sociales entre sujetos sociales o grupos que tienen ciertas características o atributos ${ }^{28}$. La manipulación se refiere básicamente a la focalización de algunas características relacionales, como eliminación de puntos no relevantes, visibilización de ciertas magnitudes de intercambio, etc. (en otras palabras, limpiar la red para poder observarla más fácilmente). La determinación de formas estructurales se hace a través de matrices y algoritmos que ayudan

\footnotetext{
${ }^{26}$ Ver por ejemplo De Nooy, 2002. En su ponencia “Una perspectiva institucional sobre la relación micromacro" publicada por esta revista en 2002, presenta una metodología que permite descubrir las relaciones entre estructuras micro y macro. Allí se privilegian unos tipos de relaciones entre unos tipos de sujetos, que fueron considerados por el mismo De Nooy como los componentes de la estructura. EI observador metodológicamente delimita estructura y sus elementos. Él mismo reconoce en su texto las dificultades metodológicas de no considerar otro tipo de elementos que seguramente hubiesen transformado parte importante de los resultados. La visualización de estas estructuras responde directamente a la experiencia del autor y delimita la realidad de acuerdo a sus prácticas precedentes. Queda por fuera un análisis amplio que a partir de un diálogo metodológico permitido por la espistemología se enriquezca la visión metodológica de los observadores.

27 Traducción del autor en: Nooy, Wouter de, Andrej Mrvar y Vladimir Batagelj. Exploratory Social Network Analysis with Pajek. New York: Cambridge University Press, 2005, p. 6
} 
identificar subgrupos, centralidades, niveles de cohesión, equivalencia estructural entre puntos de la red, etc. Finalmente la graficación simplemente se refiere a la construcción de grafos (puntos unidos por líneas) o redes (puntos que representan ciertos atributos, líneas que representan ciertos tipos de relación).

Estos procedimientos trabajan bajo el mismo supuesto de relaciones más o menos estables de intercambio y flujos. Ello denota una característica dada a la estructura: es inmóvil (dejando de lado las aplicaciones del análisis de redes en comparaciones temporales lo cual no invalida el planteamiento actual, pero complejizaría la argumentación con otro tipo de desarrollos explicativos). Pero una cosa es que sea inmóvil y otra que sea representada de forma inmóvil. Como se expuso atrás, las estructuras no son inmóviles, por el contrario, están en constante movimiento y actualización a partir de las experiencias significativas de sujetos que imprimen nuevos sentidos y que construyen nuevas formas relacionales de las heredadas. Hasta el momento el ARS empieza a incursionar en el tiempo como categoría de análisis a partir de las transformaciones mismas de las relaciones, sin embargo los usos más generalizados presentan características inmóviles de algo que es móvil.

Ello sugiere una lectura distinta de los datos presentados: las relaciones construidas como datos sociales no son la estructura, son una representación de ésta, mediada no sólo por la situación pragmática de los observadores y la doble interacción entre estructura y sujeto, sino también por la representación misma. La representación estructural se convierte en un mapa vago que propone comprensiones sistémicas a los problemas planteados en el mundo social. De esa forma lo interesante del análisis de redes sociales no será tanto la abstracción de una estructura inmanente, sino la proposición de imágenes problematizadoras diferentes del mundo social para poder ser intervenido. Sería la presentación de una herramienta para el pensamiento sistémico. Von Foester dice que "la sistémica es el arte de ver, averiguar y especialmente reconocer conexiones entre las entidades observadas"29. De esta forma, el ARS se convierte en una herramienta para generar procesos epistémicos, pero que a su vez describe datos sociales que pueden ser validados por la herencia, el proceso histórico que ha conformado

\footnotetext{
${ }^{28}$ Son dos los tipos de datos utilizados en análisis de redes: atributos y relaciones. Se recogen pues, datos relevantes a las características de sujetos $u$ organizaciones y otros relacionados con las magnitudes o existencias de intercambios o flujos.

${ }^{29}$ Von Foester, Heinz. Sistémica elemental: Desde un punto de vista superior. Medellín: Fondo editorial Universidad Eafit, 1998, p. 10
} 
ciertas funciones y operaciones, y también los actores que generan percepciones de acuerdo a su vivencia individual y su interacción con la estructura misma.

Los grafos o sociogramas no serían la representación de LA ESTRUCTURA, sino la graficación de convenciones limitadas a la experiencia de los actores que participan en el trabajo reflexivo de la investigación misma (investigadores e investigados). De esta forma, la graficación de las estructuras propondría nuevas comprensiones al accionar de los sujetos mismos al reconfigurar su visión de mundo, con respecto a sus conductas percibidas en un marco relacional. No todas las comprensiones del mundo son percibidas desde un punto de vista sistémico, lo que limita la percepción de posibilidades de acción de los sujetos mismos.

Las comprensiones generadas por el Análisis de Redes Sociales, no aportarían a una teoría general para la comprensión del mundo, o no será esta la preocupación central propuesta por este texto, sino la construcción de propuestas epistémicas para los sujetos que toman decisiones, generan comprensiones sobre su contexto y dan cuenta de diferentes posibilidades estructurales en una gran complejidad de posibilidades de configuración.

Así abrimos la puerta al ARS, tradicionalmente asociado a un paradigma explicativo, para entrar dentro de un paradigma comprensivo. Si bien lo cuantitativo se relaciona con la medición y la medición con la aceptación de instrumentos infalibles a cualquier representación de mundo, está infalibilidad ha sido puesta en tela de juicio y ha hecho del instrumento algo humano, construido por sujetos que se representan el mundo y crean convencionalmente patrones de medición que dan justo la medida de sus propias vivencias de mundo conectadas con instituciones históricas heredadas.

El resultado no es un diálogo entre comprensivo y explicativo, se va perfilando una opción que se inclina por la interpretación. Sin embargo avanzamos en la idea de arrebatar un programa metodológico considerado exclusivo del mundo explicativo a partir de un proceso de reflexividad que pone en suspenso la asociación entre medición y objetividad, agregando un componente subjetivo a la naturaleza de los datos matemáticos altamente formalizados, pero definitivamente atravesados por la semantización en situación pragmática y no como principios sociológicos imposibles de definir en el cambio constante. Será posible tal vez definir el cambio mismo como principio, pero nunca las cualidades que surgen temporalmente en el movimiento como atributos permanentes de estructuras cambiantes. 


\section{Entrevista cualitativa ${ }^{30}$}

La entrevista puede ser entendida como paquete metodológico del movimiento. La entrevista se presenta como posibilidad de acceso al mundo de las representaciones. Es el decir del hacer: el yo narrativo. La narración es continua y asociativa, genera comprensiones propias del mundo contextual. No presenta fotografías, sino historias que se desenvuelven en el tiempo, involucran múltiples categorías y relatan la realidad de forma compleja. Sin embargo sigue siendo una sola versión del mundo (imposible explorar estructuras complejas más allá de las presentadas por el hablante).

En este apartado se presentarán algunos elementos que se pueden observar en la construcción de las representaciones sociales, que son los principios constituyentes del discurso emergente en este paquete metodológico. Se presentarán primero algunos elementos del interaccionismo simbólico, teoría para la comprensión de la interacción entre entrevistador y entrevistado, pero también para la elaboración de comprensiones desde el sujeto mismo que expone su discurso. Luego se explicitarán cuatro rasgos constitutivos del discurso que narra la interacción y hace visibles las relaciones sociales que se instituyen: identidad, imágenes de mundo, territorio y socializadores. Así podremos llegar a entender como la entrevista cualitativa evidencia las prácticas individuales de los sujetos que reconstruyen el sistema de representaciones sociales.

\section{Interaccionismo simbólico: lo que se expresa en el discurso}

Los individuos, en su existencia, acumulan cierto conocimiento que les permite asumir ciertos roles dentro del mundo social. Estos roles se representan dentro de la vida cotidiana, o como Berger y Luckmann la llaman: "realidad suprema" ${ }^{31}$. Es el mundo de la representación y la externalización de los proyectos por excelencia, es precisamente donde se proyectan los roles sociales ya mencionados.

Los roles son temporales y espaciales, varían de una cultura a otra, así sea de una manera sutil. El ser joven en cierto sector, el participar de un gremio profesional, el ser madre, están tipificados dentro del contexto social y asumen unos roles específicos en su continuo hacer dentro de su contexto, lo que no implica un

\footnotetext{
${ }^{30}$ Algunos fragmentos de este apartado son tomados del trabajo inédito: Vélez Cuartas, Gabriel Jaime. La ciudad fabulada: los proyectos de comunicación en la sociedad fragmentada. Monografía de Comunicación Social-Periodismo. Universidad Pontificia Bolivariana. 1998.

${ }^{31}$ Berger y Luckmann, Op. Cit. , p. 40.
} 
determinismo, sino la construcción constante de las instituciones sociales y la imagen de lo colectivo.

Cuando A y B interactúen, como quiera que lo hagan, se producirán tipificaciones con suma rapidez. A observará a B. Atribuirá motivos a los actos de $B$ y, viendo que se repiten, tipificará los motivos recurrentes. (...) En el curso de su interacción, estas tipificaciones se expresarán en pautas específicas del comportamiento; o sea, que A y B empezarán a desempeñar roles vis à vis uno del otro, lo que ocurrirá aún cuando cada uno siga ejecutando actos diferentes del otro. ${ }^{32}$

Estos procesos se hacen en el individuo herramientas de representación para negociar sus proyectos vitales con el otro y con la colectividad. El individuo entra a formar parte de un cuerpo colectivo con estos elementos para dar vida a los proyectos de la pequeña comunidad.

Así, "mi conocimiento de la vida cotidiana se estructura en términos de relevancias, algunas de las cuales se determinan por mis propios intereses pragmáticos inmediatos, y otras por mi situación general dentro de la sociedad"33. Relevancias que ya no son las individuales, sino las colectivas en términos de los proyectos compartidos en común.

El interaccionismo simbólico permite comprender el discurso subjetivo como una construcción de relevancias estructurales que permiten describir fragmentos de estructura social en las cuales está inserto el sujeto. Pero en consecuencia con el planteamiento de las múltiples posibilidades dadas en los observadores y en los observados, expuesto anteriormente, podemos decir que la estructura reflejada y los roles identificados corresponden a una posibilidad de configuración estructural entre múltiples posibles, desde los distintos escenarios en que los sujetos se mueven. De otra forma dicho, el estructuralismo propuesto, es relativo a los observadores participantes en la construcción discursiva y las disposiciones institucionales que les anteceden. Hay tantas estructuras como escenarios de interacción son posibles, hay tantas versiones de la estructura como hablantesobservadores puedan ser entrevistados, hay tantas percepciones de lo institucional como relaciones establecidas y acuerdos generados para la creación de convenciones existan.

\footnotetext{
32 Op.cit. Berger, P. y Luckmann, T. p. 78.

33 Ibid. p. 64.
} 
La exploración de escenarios, percepciones y exploración de acuerdos puede ser definida dentro de los espacios conceptuales del territorio, la identidad o identificaciones, las imágenes y los socializadores que se constituyen en elementos de lectura básica del mundo interior de los sujetos.

\section{Territorio}

"Silva puntualiza el territorio como los espacios de prácticas sociales de autorepresentación y autoreconocimiento, lugares reales y fantasiosos que permiten crear y concebir ciertos límites colectivos" ${ }^{34}$. El territorio, como es interpretado por Armando Silva, se presenta como espacio de acción, precedido por un discurso. Son los espacios del discurso y la acción y también del discurso mismo del espacio. El espacio de la ciudad que se describe con metáforas y que se vive en las metáforas. "La ciudad, de este modo, vive también de espejismos, sus fantasmas la recorren de día y de noche. Mas no se trata de los fantasmas de los cuentos de las casas hechizadas sino del cuento de toda la ciudad"35.

El tránsito por lo urbano y lo rural, la ciudad o el campo habitados, lugares que marcan, que están Ilenos de contenido afectivo y simbólico, como también aquellos espacios ignorados, desconocidos de su contexto (ni siquiera imaginados). Espacios excluidos. Territorios del accionar grupal y territorios que no son incluidos.

Son los mapas simbólicos del territorio delimitado para su accionar, que se integra a un discurso holístico sobre el contexto físico y simbólico (se constituyen en el universo mismo). Allí el sujeto representa sus proyectos, legitima sus acciones, busca ser escuchado e interpela un público imaginario, al cual quiere persuadir de algo o simplemente la intención de persuadir se vuelve difusa o simplemente no es intención.

\footnotetext{
${ }^{34}$ RESTREPO, Mariluz. Simbología Urbana en la Propuesta de Armando Silva. En: Signo y Pensamiento. Pontificia Universidad Javeriana. Bogotá: No. 22 (primer semestre de 1993); p. 37.

${ }^{35}$ SILVA, Armando. La ciudad como arte. En: Diálogos de la comunicación. Lima. No. 40 (sep. 1994); p. 9
} 


\section{I dentidad}

La identidad no es otra cosa más que un conjunto de empalmes y desempalmes, de conexiones y desconexiones que de pronto hacen que yo sea algo en relación con alguien que no soy yo pero que de pronto le sirve como reverberancia de lo que supongo que soy, a partir de lo que ella cree que soy, de lo primero que hayan visto sus ojos. ${ }^{36}$

La identidad es un artificio, una creación que nos habla de la diferencia, que nos permite cierta estabilidad en el mundo. La identidad nos da el poder de atribuirnos características que imaginamos colectivas y que son reforzadas por costumbres que se han ido construyendo en el colectivo, pero que en realidad son abstractas, sin fundamento sólido.

No niego la posibilidad de comportamientos colectivos similares, que coinciden en celebraciones públicas, en sentimientos convertidos en masivos, en la sensación de ser comunidad en momentos especiales, pero que en la cotidianidad se diluyen y desaparecen hasta el próximo ritual de renovación de una fe puesta en una entidad completamente intangible e indefinible.

De otro modo dicho: ¿Qué me hace decir a mí que soy colombiano? ¿Hay realmente una cualidad, una sola cualidad, además de documentos que certifiquen mi identidad y que sustenten esta afirmación? Mi acento es parecido al de alguna región española, mis hábitos alimenticios perfectamente son comparables a los de un italiano o un canadiense, mi vida cotidiana podría no variar en nada a la de un estudiante universitario de la Complutense y podría escuchar perfectamente la misma música de un joven de mi edad que vive en México. Entonces: ¿Existe realmente una entidad identitaria a la que pudiera acudir, excepto la que se cumple en el imaginario de los colectivos humanos?

La identidad se reduce a una entidad espectral que no puede ser representada puesto que no es otra cosa que su representación, superficie sin fondo, reverberancia de una realidad que no existe, ni ha existido, ni existiría sino fuera precisamente por las críticas performance en que se muestra. ${ }^{37}$

\footnotetext{
${ }^{36}$ Delgado Ruiz, Manuel. Ciudad líquida, Ciudad Interrumpida. Grabación de la ponencia en el seminario: Ciudad líquida, ciudad interrumpida. (1997: Medellín). Los días 4, 5 y 6 de agosto en las instalaciones de la Biblioteca Pública Piloto.

37 Ibid, Ciudad Líquida, Ciudad Interrumpida.
} 
Así, la identidad, como parte de entidades imaginarias, está dotada de una fuerza histórica de la que se nutre, y de una fuerza interior que se ha ido construyendo en la autoafirmación de la consciencia en el transcurrir de los años y que también a la larga, por compartir juntos, vivir juntos e inclusive algunas veces construir juntos una historia durante mucho tiempo (a través de generaciones), se han ido tejiendo hilos invisibles, entramados difíciles de romper para algunos casos (nacionalismos, regionalismos, luchas étnicas) o que en la fragmentación actual y la sociedad globalizada se diluyen por no tener historias comunes que contar.

La identidad es la primera entidad imaginaria que se constituye en el sujeto, de allí parten las otras formaciones de imágenes (que alimentan el discurso sobre el mundo). $Y$ no porque la identidad se solidifique como base o soporte, sino porque es el principio sobre el cual se negocian imágenes y proyectos, pero que a la vez ese principio puede ser modificado en la negociación o reafirmado como mi posición inmodificable en el mundo.

La identidad entonces se constituye como un conjunto de imágenes y memorias que hacen sentir parte de un colectivo y que además impulsan a construir en conjunto. Es la descripción perfecta que puede hacer un sujeto sobre sí mismo y sobre el colectivo al que pertenece, sea éste, de la naturaleza que sea.

\section{I mágenes}

Las imágenes por contraposición a la identidad pero en relación fluida, bidireccional, se constituirán no sólo en aquellas pre-descripciones que residen en la memoria, el consciente y el inconsciente que se hacen materia prima de la narración en el discurso de lo que soy y por consiguiente de lo que no soy, sino también de todas aquellas que hacen parte del discurso del sujeto que explican el mundo, que se expanden más allá de la autodescripción, pero que también hablan de lo que el sujeto es en relación perspectiva del universo del cual hace parte.

En un sentido más amplio, las imágenes son lecturas de mundo ya asimiladas al discurso proyectado, que han entrado a hacer parte del mundo del sujeto.

Pero entender aquí el concepto de imagen, es hacerlo de un modo genérico. No lo limito a la descripción visual del contexto, sino a lo que la sociedad audiovisual ha logrado introducir en los conceptos que leen al mundo: imagen como descripción de situaciones que quedan en la memoria, imagen como sensación perceptual evocada por el discurso y atribuida a cualquier órgano de los sentidos y finalmente, imagen tomada como representación audiovisual del mundo, de un mundo que deviene en los parámetros estéticos: de música, de slogans, de modas, etcétera... es la 
manera descriptiva de García Canclini que, por ejemplo, propone: “Ahora la ciudad es como un videoclip: montaje efervescente de imágenes discontinuas"38.

La imagen, la imaginación, lo imaginario, parecen hundirse y prolongarse en el flujo temporal, y, sin embargo, la esencia de lo imaginario se sitúa quizá en la evocación, en la resurrección del pasado; es decir, en una repetición. Esta acercaría la imagen al recuerdo, y lo imaginario, a la memoria y al conocimiento. ${ }^{39}$ Las imágenes constituyen el conocimiento, la realidad objetivada, el mundo percibido como conocimientos, como discursos, es la construcción del orden. Según Berger y Luckmann: “El conocimiento primario con respecto al orden institucional situado en el plano preteórico: es la suma total de lo que todos saben sobre el mundo social, un conjunto de máximas, moralejas, granitos de sabiduría proverbial, valores y creencias, mitos, etc." ${ }^{40}$. Es precisamente ese plano de las imágenes mismas. Imágenes que se hacen fundamento discursivo del sujeto.

Se llega a organizar de ese modo un todo discursivo, una fábula del mundo, con tintes dogmáticos, ideologizados, utópicos (si se piensa en la utopía como en el no presente y la idealización del mundo), heterotópicos si se piensa al pequeño colectivo dentro de un contexto global. Pero un discurso también impregnado de toda la afectividad y la situación personal de cada uno y una de sus integrantes y del discurso de las instituciones que están presentes en su contexto.

\section{Socializadores}

Los socializadores son todas las instituciones sociales formadas y que de un modo u otro alimentan el discurso de los grupos. En muchos casos algunos pueden llegar a convertirse regentes del discurso holístico manejado y moldeado por los sujetos y grupos mismos, pero nunca involuntario a no ser por eventos excepcionales como el hostigamiento o la cooptación.

Hacen parte del contexto grupal, de la conformación institucional de lo social, pero representan a la vez fragmentos del conocimiento social, que son involucrados en el discurso de la pequeña comunidad y leídos en clave propia.

\footnotetext{
38 Garcia Canclini, Néstor. Consumidores y ciudadanos: conflictos multiculturales de la globalización. México D.F: Editorial Grijalbo, 1995. p.100

39 Lefevbre, Henri. La vida cotidiana en el mundo moderno. Madrid: Alianza editorial, 1972, p. 29

${ }^{40}$ Op.cit. Berger y Luckmann. p 88
} 
El discurso institucional o sus fragmentos, pasan a formar parte del todo discursivo del grupo.

Socializadores son instituciones sociales: la familia, las iglesias, los sistemas de atención social, la administración pública, en fin, todas aquellas que son percibidas desde la pequeña comunidad y por sus integrantes.

Pero también están los medios masivos, que además de conformarse como instituciones sociales, recuperan el todo social y lo representan fragmentado y especializado. Los medios masivos se constituyen como socializadores, espacios de representación posible y de reconocimiento y legitimación de acciones de una manera especial. Son, por decirlo de algún modo, fuente primaria de consulta de lo que constituye el conocimiento epocal.

Hasta aquí los aspectos constitutivos de la representación social y la construcción de imágenes de mundo.

Las relaciones sociales expresadas en la entrevista cualitativa, son imágenes, percepciones de flujos e intercambios, interacciones narradas y explicadas desde las propias experiencias. Podríamos llamarlas versiones de estructuras. El sujeto lee su mundo y lo pone en juego a través del lenguaje, es ese lenguaje el que da cuenta de las posibilidades del sujeto, no únicamente las contingencias expresadas de forma objetiva, como se pretende tal vez desde el paradigma explicativo. Eso es lo visible en la entrevista cualitativa, no hay una naturaleza distinta en lo enunciado. No hay rastros de estructuras inmanentes que van más allá de los sujetos mismos, no puede existir algo distinto que lo percibido por el sujeto entrevistado.

La pretensión de generalidad del investigador es un discurso autorreferente, no con referencia a las representaciones emergentes del sujeto (interlocutor). El discurso del investigador sería otra versión más de la realidad, que entra en diálogo con la propia versión del entrevistado instaurando un ciclo de representaciones que se negocian con otras representaciones.

Las estructuras presentadas por quien guía el discurso (el hablante) son sólo las posibilidades leídas por el mismo actor que tiene constricciones institucionales. No se pretende plantear que el mundo está condicionado al discurso creador de un solo actor y que cada discurso crea un nuevo mundo y vivimos en una sociedad autista. Sólo es la descripción de la naturaleza real de los datos. Los hechos evidenciados en la entrevista no van más allá de lo enunciado, y eso enunciado se materializa en 
las únicas posibilidades dadas por las representaciones construidas por el hablante, convertidas por el entrevistador en datos de investigación, pero que han sido antecedidos por una negociación de representaciones entre entrevistador y entrevistado. El resto son agregados analíticos propuestos por quien entrevista, asocia y relaciona.

El supuesto de la posibilidad de negociación de representaciones en la aplicación del programa metodológico, es el punto más importante que permitirá presentar la posibilidad de una articulación entre el ARS y la entrevista cualitativa.

No se pretende abandonar la formalización matemática propuesta por el ARS, pero tampoco generar una identidad entre formalización y verdad o realidad estructural. La formalización permite construir referentes precisos, construidos sobre discursos que son expresión de representaciones de mundo. La formalización sucede a la representación, no al contrario. La formalización es construida desde el lenguaje y el lenguaje es adoptado en circunstancias pragmáticas que permiten, a partir de múltiples ejercicios reflexivos y de negociación de representaciones con otros, crear ciertas convenciones. El crear convenciones, permite su institucionalización, esa institucionalización permite generar precisamente lenguajes formales para el desarrollo de argumentos de carácter lógico que ayuden a la toma de decisiones en estructuras complejas. Esas decisiones afectan de manera directa la realidad y comienza de nuevo el ciclo de construcción de representaciones sobre los resultados de las decisiones y sobre los factores externos que afectan el proceso emprendido o el desenvolvimiento de las relaciones sociales mismas. No es una única lógica pero podría enmarcarse dentro de las pretensiones reflexivas de esta alta modernidad proclamada también por Giddens ${ }^{41}$.

Pero aquí habría que distinguir convenciones institucionalizadas por acuerdos históricos, inclusive heredados, de representaciones sociales constituidas en la práctica de los sujetos. El análisis de redes sociales permitiría observar los primeros, la entrevista cualitativa las segundas. El diálogo metodológico es expresión de una relación entre instituciones y representaciones sociales, ambas necesarias para observar las estructuras sociales y los procesos mismos de su estructuración.

\footnotetext{
${ }^{41}$ Ver: Giddens, Anthony. Las consecuencias de la modernidad. Madrid: Alianza Universidad, 1994
} 
El papel del investigador es esencial para poder generar instrumentos que permitan desarrollar reflexividad no entendida como autoconciencia, sino como capacidad de generar problematizaciones apropiadas y aportar nuevas preguntas que permitan generar dinámicas sociales de producción de conocimiento en comunidades y procesos de construcción colectiva.

Faltarían unos últimos apuntes acerca de la fundamentación epistemológica de un diálogo entre estructura y sujeto, introduciendo la relación investigador-objeto.

\section{Un interludio antes de argumentar esta articulación metodológica en la doble hermenéutica y la dualidad de estructura}

Antes de continuar con la exposición de la doble hermenéutica como fundamento epistemológico de este diálogo metodológico, es importante insistir en el carácter de la argumentación presentada hasta el momento. La pretensión ha sido desligar los paquetes metodológicos expuestos, especialmente el de Análisis de Redes Sociales de planteamientos positivistas dentro de paradigmas de corte explicativo, que permitan revisar el uso de la herramienta desde otro tipo de visiones pragmáticas que permiten entender la realidad desde las construcción lingüísticas y semánticas dando un uso pragmático a las comprensiones de mundo.

Fielding \& Fielding afirman que se “deberían combinar teorías y métodos cuidadosa y propositivamente con la intención de adicionar extensión y profundidad a nuestros análisis, pero no con el propósito de perseguir la verdad objetiva" ${ }^{42}$. La combinación de metodologías, no de forma complementaria sino articulada en una visión de mundo que permita generar nuevas comprensiones, complejiza la lectura de la realidad, enriqueciéndola con nueva visiones.

\footnotetext{
42 Traducción del autor del texto: "We should combine theories and methods carefully and purposefully with the intention of adding breadth and depth to our analysis, but not for the purpose of pursuing objective truth." (p.33) En: Fielding, N., \& Fielding, J. (1986). Linking data. Beverly Hills, CA: Sage Publications. Tomado de Chong Ho Yu. Misconceived relationships between logical positivism and quantitative research. Paper presented at the Annual Meeting of the 2001 American Educational Research Association, Seattle, WA. Published in Research Method Forum, 2003 http://www.aom. pace.edu/rmd/2002forum.html. Revised on July 18, 2005. Forthcoming in the book Philosophical foundations of quantitative research methodology as a chapter (Laham, MD: University Press of America). En línea: http://seamonkey.ed.asu.edu/ alex/computer/sas/positivism.pdf Tomado el 9 de diciembre de 2005. p. 27
} 
Las formas cualitativas y cuantitativas de investigación tienen sus propios papeles que desempeñar en la teorízación. El asunto no es si usar una forma u otra sino más bien cómo pueden funcionar estas formas para impulsar la construcción de una teoría. Aunque la mayor parte de los investigadores tienden a usar métodos cualitativos y cuantitativos de formas complementarias, abogamos por una verdadera interacción entre ambas. Lo cualitativo debe dirigir lo cuantitativo, y lo cuantitativo retroalimentarse de lo cualitativo en un proceso circular pero al mismo tiempo evolutivo, con cada método contribuyendo en la forma en que sólo él puede hacerlo." 43

Sin embargo, hay un malentendido que simplifica especialmente a las metodologías cuantitativas en un solo paradigma y este paradigma está asociado por lo regular a al positivismo lógico que busca entre otros asuntos generar datos que permitan observar regularidades y encontrar validaciones lógicas a los enunciados explicativos, perdiendo de vista el sentido explicativo causal que podría ser visto desde diversos puntos de vista epistemológicos. Chong Ho Yu llega a plantear inclusive que el concepto de paradigma asociado a los planteamientos Kuhnianos, podría ser poco útil al momento de generar propuestas metodológicas, por las limitaciones que presenta al momento de abordar explicaciones o comprensiones de la realidad misma.

De acuerdo con Kuhn (1962), siguiendo un paradigma, todos los miembros de un comunidad científica específica aceptan un grupo de postulados comunes acordados. Sin embargo, es dudable que la teoría del paradigma de Kuhn pueda ser aplicada a una rica colección de epistemologías y metodologías en investigación cuantitativa. Laudan (1977) argumenta que la teoría del paradigma no encaja con la historia de la ciencia. Es más, no es poco frecuente para un número de teorías en competencia basadas en postulados incompatibles, coexistir. Así Laudan propuso el concepto de 'tradición investigativa' para reemplazar el concepto de 'paradigma. Laudan no está solo. En reacción a la visión de la investigación cuantitativa desde una aproximación positivista, Clark (1998) acoge el punto de vista de que la investigación cuantitativa está enmarcada por más de una filosofía. ${ }^{44}$

\footnotetext{
${ }^{43}$ Strauss, Anselm y Juliet Corbin. Bases de la investigación cualitativa: técnicas y procedimientos para desarrollar la teoría fundamentada. Medellín: Universidad de Antioquia, 2002, p.p. 37-38

${ }^{44}$ Opcit. Chong p. 5 Traducción del autor del texto: “According to Kuhn (1962), following a paradigm, all members of a specific scientific community accept a set of commonly agreed exemplars. However, it is doubtful whether the Kuhnian paradigm theory could be applied to such a rich collection of epistemologies and methodologies in quantitative research. Laudan (1977) argued that the paradigm theory does not fit with the history of science. Indeed, it is not uncommon for a number of competing theories based upon incompatible exemplars to coexist. Thus, Laudan proposed the concept of "research tradition" in an attempt to replace "paradigm." Laudan is not alone. In reaction to the viewing of quantitative research as a positivist approach, Clark (1998) embraced the view that quantitative research is shaped by more than one philosophy."
} 
El propósito hasta el momento ha sido el intentar demostrar que un paquete metodológico cuantitativo puede ser leído desde perspectivas diferentes a las planteadas por paradigmas explicativos y generar un piso argumentativo que dé lugar a entender que no es posible ver esbozos estructurales de representaciones individuales. Desde esta perspectiva dialogal es que puede abrirse una concepción de corte epistemológico dentro de la investigación empírico-analítica como la doble hermenéutica y el planteamiento de la dualidad de estructura de Giddens.

\section{Doble hermenéutica y dualidad de estructura}

La comprensión de los programas metodológicos ${ }^{45}$ desde la naturaleza de los datos que producen y no únicamente desde el paradigma metodológico desde el cual se plantean, permite avanzar en el poder descriptivo de estos y dejar en suspenso la fundamentación epistemológica desde la cual se erigen. Esto puede ser muy útil para tratar de emprender un diálogo real entre descripciones que hagan una objetivación del mundo (no mirar al mundo de forma objetiva) y otras que pongan de relieve la naturaleza subjetiva de la construcción del conocimiento.

A ello diría Giddens en la configuración del objeto que se propone en este texto:

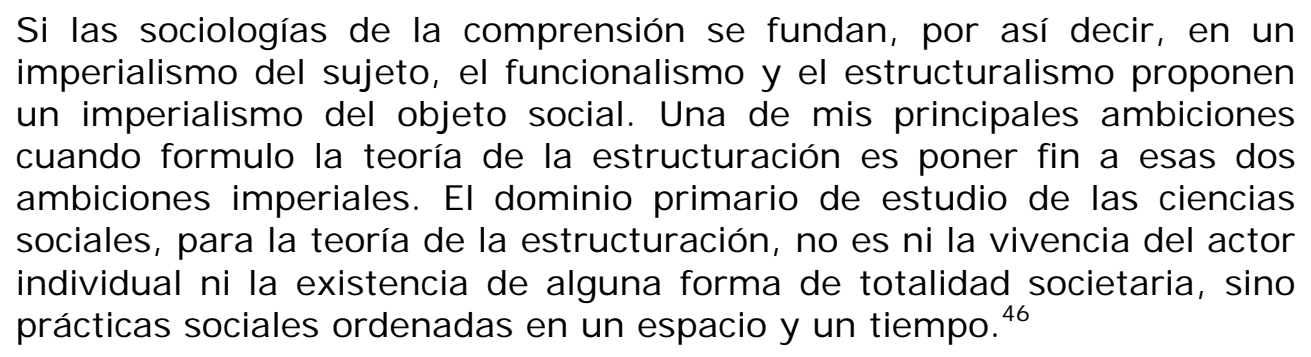

Pero este planteamiento se debe al fallo de la separación entre la estructura como objeto y el sujeto como objeto. Esta separación, insondable entre los más radicales de ambos bandos, generó profundas brechas que se manifestaron de forma definitiva en el mundo social, generando problemas no sólo epistemológicos, sino también operativos en el mundo para el desarrollo de la propuesta moderna. Estos

\footnotetext{
45 Esta acepción de los marcos metodológicos puede encontrarse en Opcit. Galindo Cáceres, Jesús. Técnicas de Investigación en Sociedad, Cultura y Comunicación. México: Addison Wesley Longman, 1998. En este texto hace un recorrido de corte heterodoxo por distintos abordajes metodológicos cualitativos y cuantitativos y centra su atención en la elección de metodologías a partir de los objetos de estudio y sus características, más que en la concepción teórica o el paradigma, sea explicativo o compresivo, desde el cual podrían construirse los programas metodológicos en una investigación. De hecho, deja a una lado la dicotomía entre cuali y cuanti y propone una clasificación entre metodologías de profundidad y de extensión, según el tipo de objeto de estudio abordado.
}

${ }^{46}$ Giddens, p. 40 
son algunos de los planteamientos propuestos por Giddens acerca de los problemas actuales de las ciencias sociales:

- "Sostendré que la desorientación, que se expresa a sí misma en la opinión de que no es posible obtener un conocimiento sistemático de la organización social, resulta en primer lugar de la sensación que muchos de nosotros tenemos de haber sido atrapados en un universo de acontecimientos que no logramos entender del todo y que en gran medida parecen escapar al control." 47

- "La reflexión de la vida social moderna consiste en el hecho de que las prácticas sociales son examinadas constantemente y reformadas a la luz de nueva información sobre esas mismas prácticas, que de esa manera alteran su carácter constituyente". ${ }^{48}$

- "Nos encontramos en un mundo totalmente constituido a través del conocimiento aplicado reflexivamente, pero en donde al mismo tiempo nunca podemos estar seguros de que no será revisado algún elemento dado de ese conocimiento." 49

- “Las ciencias sociales están más profundamente implicadas en la modernidad de lo que están las ciencias naturales porque la arraigada revisión de las prácticas sociales, a la luz del conocimiento sobre esas mismas prácticas, forma parte del auténtico tejido de las instituciones modernas."

- "La cuestión no radica en que no exista un mundo social estable para ser conocido, sino que el conocimiento de ese mundo contribuye a su carácter cambiante e inestable." ${ }^{" 51}$

Giddens le apuesta a la construcción de una teoría general, que permita el estudio de particularidades en configuraciones específicas, teniendo en cuenta un contexto global, extendido de la modernidad. Pero debido a los múltiples rasgos y formas de configuración, sólo es posible generar comprensiones en espacios y territorios específicos, atravesados por una gran cantidad de fenómenos ${ }^{52}$.

De lo anterior se desprende que:

1. La sociología no se ocupa de un universo "pre-dado" de objetos, sino de uno que está constituido o es producido por los procederes (acciones) activos de los sujetos.

\footnotetext{
${ }^{47}$ GIDDENS, Anthony. Consecuencias de la Modernidad. Madrid: Editorial Alianza, 1994. p. 16

48 I bid p. 46

49 I bid p. 47

50 I bid p. 48

51 Ibid p. 51

52 Estos fenómenos según Giddens están atravesados por tres principios rectores constituyentes de la modernidad reflexividad, desanclaje y separación del espacio y el tiempo (conceptos que no se desarrollarán por su extensión y por no aportar a la discusión epistemológica que hemos planteado). Para ampliación de estos conceptos ver: Giddens. Opcit. Las Consecuencias de la Modernidad.
} 
2. Por consiguiente, la producción y reproducción de la sociedad ha de ser considerada como una realización inteligente por parte de sus miembros, no como una mera mecánica de procesos. ${ }^{53}$

Pero no se puede negar la existencia de estructuras institucionalizadas en el tiempo y que han sido precedentes a la acción de cualquier sujeto. El diálogo entre sujeto y estructura, Giddens le da el nombre de agencia y es la presencia de formas institucionalizadas en el sujeto pero que son reinterpretadas y transformadas por las representaciones generadas en el actuar mismo de estos. Esto es conocido como dualidad de estructura.

Pero no es únicamente la configuración de un objeto de estudio lo que preocupa a Giddens también es la naturaleza del observador. Quien observa se introduce en un mundo que le es ajeno y tiene sus propias configuraciones y comprensiones de mundo. El observador llega con unas estructuras predispuestas y dadas por un lenguaje de tipo disciplinar. Su tarea es comprender las comprensiones de otros en sus propias construcciones y llevarlas a otras formas de construcción. Así se plantea la doble hermenéutica.

El doble juego de la visualización de estructuras definidas institucionalmente y la interpretación de estas desde las representaciones sociales construidas en el diálogo entre observadores (investigador $e$ investigados en una doble hermenéutica) se constituyen en las bases epistemológicas de un diálogo metodológico entre paquetes tradicionalmente divorciados en concepciones erróneas acerca de las formas de hacer investigación. Por un lado el investigador retoma instituciones socialmente construidas y construye los datos para hacerlos visibles, de otro lado reconstruye la presentación de esa estructura con los diálogos que permiten la emergencia de representaciones sociales que pueden ayudar a entender la reconfiguración de esas mismas estructuras y las posiciones adoptadas así como las decisiones tomadas que pueden predecir el cambio social o por lo menos diagnosticarlo. Lo antes inmóvil se hace dinámico y lo que se percibía como dinámico, puede ser fotografiado, no sólo generando nuevo conocimiento, sino también nuevas actitudes en los sujetos participantes de un proceso que determina construcciones nuevas de conocimiento

Estructura y sujeto, encuentran articulación no sólo conceptual sino también metodológica desde un punto de vista epistémico.

${ }^{53}$ Opcti. Briones p. 69. tomado de Giddens, Anthony. Las nuevas reglas del método sociológico. Buenos 


\section{Bibliografía}

Berger, Peter y Thomas Luckmann (1978). La Construcción Social de la Realidad. Buenos Aires: Amorrourtu.

Briones, Guillermo (2002). Epistemología de las Ciencias Sociales. Bogotá: ARFO Editores.

Chong Ho Yu (2005). “Misconceived Relationships Between Logical Positivism And Quantitative Research". Paper Presented At The Annual Meeting Of The 2001 American Educational Research Association, Seattle, WA. Published In Research Method Forum, 2003 <http://Www.Aom.Pace.Edu/Rmd/2002forum.html>. Revised On July 18, 2005. Forthcoming In The Book Philosophical Foundations Of Quantitative Research Methodology As A Chapter (Laham, MD: University Press Of America). En Línea:

<http://Seamonkey.Ed.Asu.Edu/ Alex/Computer/Sas/Positivism>.

Deladalle, Gérard (1996). Leer a Peirce Hoy. Barcelona: Gedisa

Delgado Ruíz, Manuel. “Ciudad Líquida, Ciudad Interrumpida”. Grabación De La Ponencia En El Seminario: Ciudad Líquida, Ciudad Interrumpida. (1997: Medellín). Los Días 4, 5 Y 6 De Agosto En Las Instalaciones De La Biblioteca Pública Piloto.

Galindo Cáceres, Jesús (1998). Técnicas de Investigación en Sociedad, Cultura y Comunicación. México: Addison Wesley Longman.

García Canclini, Néstor (1995). Consumidores y Ciudadanos: Conflictos Multiculturales de la Globalización. México D.F: Editorial Grijalbo.

Giddens, Anthony (1994). Las Consecuencias de la Modernidad. Madrid: Alianza.

Giddens, Anthony (1995). La Constitución de la Sociedad. Bases para la teoría de la estructuración. Buenos Aires: Amorrortu editores.

Ibáñez, Jesús (1998). “Los Avatares Del Sujeto”. En: Ibáñez, Jesús (Comp.) Nuevos Avances En La Investigación Social I. Barcelona: Proyecto A.

Lefevbre, Henri (1972). La Vida Cotidiana en el Mundo Moderno. Madrid: Alianza Editorial. 
Nadel, S. F. (1966). Teoría de la Estructura Social. Guadarrama: Madrid.

De Nooy, Wouter, Andrej Mrvar y Vladimir Batagelj (2005). Exploratory Social Network Analysis with Pajek. New York: Cambridge University Press.

De Nooy, Wouter (2002). “Una perspectiva institucional sobre la relación micromacro". En línea: http://revista-redes.rediris.es Redes- Revista Hispana para el Análisis de Redes Sociales. Vol. 3 No. 5, septiembre-noviembre.

Peirce, Charles Santiago Sanders (1988). El Hombre, Un Signo: El Pragmatismo de Peirce. Barcelona: Editorial Crítica.

Pizarro, Narciso (1998). Tratado de Metodología de las Ciencias Sociales. Madrid: Siglo XXI.

Restrepo, Mariluz (1993). "Simbología Urbana en la Propuesta de Armando Silva". En: Signo y Pensamiento. Pontificia Universidad Javeriana. Bogotá: No. 22 (Primer Semestre)

Saussure, Ferdinand de (1974). "Curso de Lingüística General”. Argentina: Losada.

Silva, Armando (1994). "La Ciudad Como Arte”. En: Diálogos de la Comunicación. Lima. No. 40 (Septiembre).

Strauss, Anselm y Juliet Corbin (2002). Bases de la Investigación Cualitativa: Técnicas y Procedimientos para Desarrollar la Teoría Fundamentada. Medellín: Universidad de Antioquia.

Van Dijk, Teun (1980). Texto y Contexto. Madrid: Cátedra.

Varela, Francisco (1998). “Historia de la Reflexividad”. En: Ibáñez, Jesús (Comp.) Nuevos Avances En La Investigación Social I. Barcelona: Proyecto A

Vélez Cuartas, Gabriel (2005). "Semiótica y Acción Comunicativa: Una Ruta entre Pierce, Apel y Habermas", En: Andamios. Revista De Investigación Social, Año 1, Número 2, Junio 2005, Colegio De Humanidades Y Ciencias Sociales, Universidad Autónoma De La Ciudad De México, Pp. 173-195

Vélez Cuartas, Gabriel Jaime (1998). “La Ciudad Fabulada: Los Proyectos De Comunicación En La Sociedad Fragmentada". Monografía De Comunicación SocialPeriodismo. Universidad Pontificia Bolivariana. 
Von Foester, Heinz (1998). Sistémica Elemental: Desde Un Punto De Vista Superior. Medellín: Fondo Editorial Universidad Eafit.

Wellman, Barry (1999). “El Análisis Estructural: Del Método y la Metáfora a la Teoría y la Sustancia". Monográfico Análisis De Redes Sociales: La Consolidación De Un Paradigma Interdisciplinar. Madrid, 22 De Junio (Número 33). En Línea: http://www.ucm.es/info/pecar/docu.htm 